\title{
Molecular modelling of a chemodosimeter for the selective detection of As(III) ion in water
}

\author{
SAIRAM S MALLAJOSYULA, USHA H, AYAN DATTA and SWAPAN K PATI* \\ Theoretical Sciences Unit, Jawaharlal Nehru Center for Advanced Scientific Research, \\ Jakkur Campus, Bangalore 560064 \\ e-mail: pati@jncasr.ac.in
}

\begin{abstract}
We have modelled for the first time a chemodosimeter for As(III) detection in water. The chemodosimeter modelled is a 1,3-dithiole-2-thione derivative with an anthracene unit which has been previously described as a chemodosimeter for $\mathrm{Hg}(\mathrm{II})$ detection. Quantum chemical calculations at the DFT level have been used to describe the binding energies and selectivity of the chemodosimeter. We find that the dosimeter action is intrinsically dependent on the thiophillic affinity and the coordination sphere of the metal ion. Binding studies for a series of metal ions: $\mathrm{Pb}(\mathrm{II}), \mathrm{Cd}(\mathrm{II}), \mathrm{Hg}(\mathrm{II}), \mathrm{Ni}(\mathrm{II})$ and As(III) followed by an analysis of the complete reaction pathway explains the high selectivity of the dosimeter towards As(III). The dosimeter efficiency is calculated as $66 \%$ for As(III)-ion.
\end{abstract}

Keywords. Density functional theory; chemodosimeter; arsenic detection.

\section{Introduction}

Arsenic poisoning is a major health concern effecting huge human populations all over the world. There are three major types of arsenic poisoning, the first is arsenic poisoning associated with geothermal water as found in hot springs of Yellowstone Park in USA, the second type being associated with arsenic from mining operations and agricultural pesticide run-off which also affect many parts of the world and the third kind being arsenic poisoning of aquifers which has adversely affected the Ganges delta region of West Bengal and Bangladesh. ${ }^{1-4}$ The alarming nature of this problem in the Ganges delta regions is due to the presence of soluble arsenic(III) ion in ground water which is the most common source of drinking water in these areas. The distribution of arsenic(III) ion and its concentration levels from various water sources in these areas has been extensively studied..$^{5-7}$ The concentration levels of arsenic(III) ion in the areas effected by arsenic poisoning can reach as high as $1000 \mu \mathrm{g} / 1$ which is well above the WHO (World Health Organization) standard of $10 \mu \mathrm{g} / 1 .{ }^{1-7}$ Such high levels of arsenic cause severe skin diseases including skin cancer; lung, bladder, and kidney cancers, and other internal tumours, peripheral vascular disease, hypertension, and diabetes. It also seems to

\footnotetext{
${ }^{\dagger}$ Dedicated to Prof. C N R Rao on his 75th birthday

*For correspondence
}

have a negative impact on reproductive process (infant mortality and weight of newborn babies) ${ }^{8,9}$ The detection of $\mathrm{As}(\mathrm{III})$ at low concentration limits (ppm, ppb) in ground water will thus be helpful in identifying contaminated sources of drinking water. Various analytical detection techniques are used to detect Arsenic(III) at these concentration levels, such as high-performance liquid chromatography (HPLC), ${ }^{10}$ Atomic Absorption Spectroscopy (AAS) ${ }^{11}$, and a combination of the two methods such as highperformance liquid chromatography-inductively coupled plasma mass spectrometry (HPLC-ICPMS). ${ }^{12}$ Though such analytical detection techniques are highly accurate, they require expensive instruments with clean laboratory conditions and proper sample preparations. This calls for the development of new cost-effective and portable methods for selective Arsenic(III) detection.

Optical and electrochemical probes for the detection of analyte have been successfully used in the development of alternate detection techniques. Some of these methods use chemical molecules as probes to generate an analytical signal upon interacting with the target analyte. ${ }^{13}$ These detection techniques have been successfully developed for the fluoregenic ${ }^{14}$ and chromogenic ${ }^{15}$ detection of $\mathrm{Hg}^{2+}$ and $\mathrm{Cu}^{2+}$ ions in aqueous solutions. Compared to the relatively welldeveloped fluorescent sensors, development of fluorescent chemodosimeters has recently emerged as a research area of significant importance. ${ }^{16}$ Chemodo- 
simeters detect an analyte through a highly selective and usually irreversible chemical reaction between the dosimeter molecule and the target analyte leading to an observable signal, in which an accumulative effect is directly related to the analyte concentration. Using this principle, chemodosimeters for the selective detection of $\mathrm{Hg}^{2+}$ have been recently reported, these dosimeters make use of the strong thiophillic affinity of the $\mathrm{Hg}^{2+}$ to bring about mercury-promoted desulfurization reaction, which is the key step to $\mathrm{Hg}^{2+}$ detection. ${ }^{17}$ The selective nature of chemodosimeter reactions makes them interesting candidates for a complete quantum chemical investigation and elucidation of the reaction pathways. We have undertaken a complete mechanistic study of the $\mathrm{Hg}$ (II) and As(III) reactions with the dosimeter for describing their chemodosimeter reaction. The model system for our calculations (4-[2-methyl]thio-1,3-dithiole-2thione) is based on the chemodosimeter as described by Zhang et al. ${ }^{17(\mathrm{~d})}$ From our calculations we find that the selectivity of the reaction depends on the coordination sphere of the metal ion that controls the selectivity criteria.

In the next section, we examine the thiophillic affinity, reaction sites and the binding energy of the chemodosimeter towards various metal ions. Followed by this, we consider the effects of solvation and the coordination spheres for the dosimeter-metal complexes. Next, we consider the mechanistic processes in the selective reactions and consider the structures of the intermediates and the transition states. Finally, we conclude the paper with a summary of all the results.

\section{Computational details}

The molecular orbital DFT calculations have been carried out using the Gaussian 03 program. ${ }^{18} \mathrm{We}$ have used the B3LYP functional; three-parameter hybrid functional of Becke, with the Lee, Yang, and Parr correlation functional for all the calculations. ${ }^{19}$ The LanL2DZ basis set is used for all calculations, which uses an all-electron description for the firstrow elements (D95), and an ECP (effective core potential) for inner electrons and double- $\zeta$ quality valence functions for the heavier elements. ${ }^{20}$ TDDFT (Time dependent density functional theory) calculations have been used to calculate the dipole allowed transitions and the oscillator strengths (f) ${ }^{21}$ For a description of the reaction mechanism we have considered the coordination sphere of the metal ion involved in the reaction. All the intermediate structures in the reaction pathway were fully optimized with no geometry constraints imposed during the calculations. For the Ni systems, we have performed the calculations using the UB3LYP functional at the same basis set level.

\section{Results and discussion}

\subsection{Selectivity of dosimeter}

Both As (III) and $\mathrm{Hg}$ (II) have a special affinity towards sulfur. This results from the favourable softsoft acid-base interactions between them. Many As(III) ores are known to contain sulfur like Orpiment $\left(\mathrm{As}_{2} \mathrm{~S}_{3}\right)$, Realgar $\left(\mathrm{As}_{4} \mathrm{~S}_{4}\right)$, and Arsenopyrite (FeAsS). Similarly, the most common ore of $\mathrm{Hg}$ (II) is Cinnabar $(\mathrm{HgS})$. We have probed the selectivity of 4-[2methyl]thio-1,3-dithiole-2-thione towards both As(III) and $\mathrm{Hg}(\mathrm{II})$ and the calculations show that it is more selective towards the As(III) ion.

1,3-dithiole-2-thione derivative featuring an anthracene unit: 4-[2-(9-anthryloxy)ethyl]thio-1,3dithiole-2-thione] (1) has been utilized as chemodosimeter for $\mathrm{Hg}^{2+}$ detection. ${ }^{17(\mathrm{~d})}$ The chemodosimeter detects $\mathrm{Hg}^{2+}$ from a host of other metal ions like, $\mathrm{Ag}^{+}, \mathrm{Pb}^{2+}, \mathrm{Cu}^{2+}, \mathrm{Ni}^{2+}, \mathrm{Cd}^{2+}, \mathrm{Mn}^{2+}$, etc. The chemical reaction between compound 1 and $\mathrm{Hg}^{2+}$ results in the formation of a highly fluorescent 1,3-dithiole-2-one (2) derivative of compound 1 (figure 1). The origin of fluorescence is traced to the differences between the photo-induced electron transfer between compounds 1, 2 and the anthracene unit. The TD-DFT calculations reveal that the absorptions for the reactant (1) occurs at $333.46 \mathrm{~nm}$ (HOMO to LUMO, $f=0 \cdot 12$ ), the product (2) at $270 \cdot 14 \mathrm{~nm}$ (HOMO to LUMO + 1, $f=0.04)$ and anthracene occurs at $391.83 \mathrm{~nm}$ (HOMO to LUMO, $f=0.09$ ). The calculated absorption wavelengths compare fairly well with the experimental findings, ${ }^{17(\mathrm{~d})}$ thereby validating the B3LYP/LANL2DZ level calculations, which

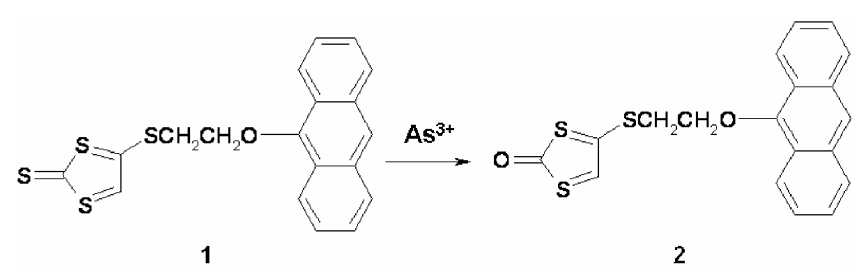

Figure 1. Transformation of compound $\mathbf{1}$ to $\mathbf{2}$ in the presence of metal ions like $\mathrm{As}(\mathrm{III})$ and $\mathrm{Hg}(\mathrm{II})$. 


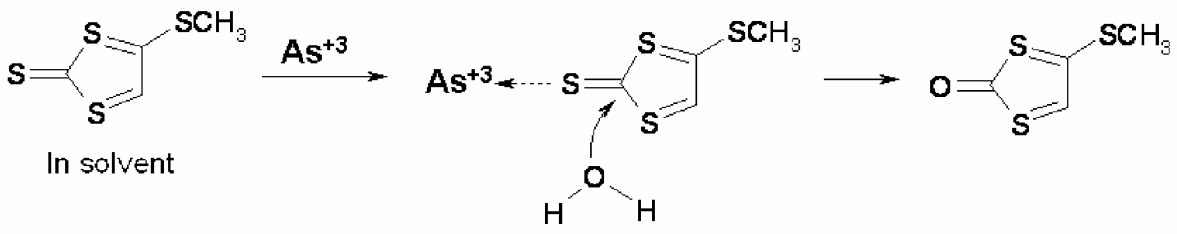

Neucleophillic Attack

Scheme 1. Metal reactant complexation leads to the formation of an electron deficient $\mathrm{C}$ center which is liable to a neucleophillic attack. Where $\mathrm{M}$ is As(III) or $\mathrm{Hg}(\mathrm{II})$.
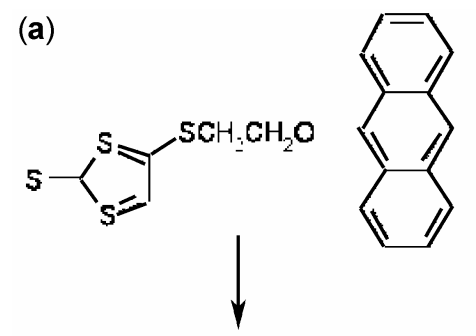

(b)
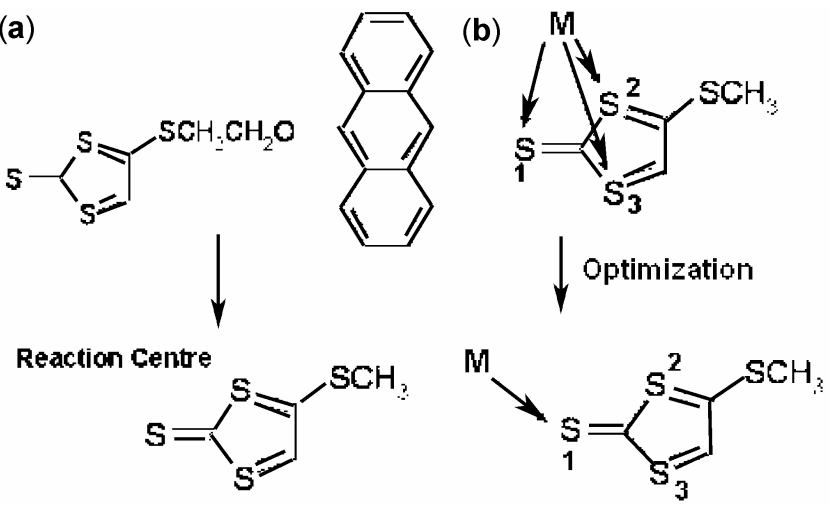

Figure 2. (a) Defining the reaction center for the binding studies; (b) Metal ions prefer binding to site 1 compared to sites $\mathbf{2}$ and $\mathbf{3}$.

we further use for determining the dosimetric action of the ligand towards the As(III)ion. The dosimeter action critically depends on the presence of water, which acts as the source of oxygen in the conversion of 1,3-dithiole-2-thione (R) to 1,3-dithiole-2-one (P).

\subsection{Binding studies}

The chemical transformation of compound 1 to 2 involves the conversion of the $\mathrm{C}=\mathrm{S}$ to $\mathrm{C}=\mathrm{O}$. We note that the anthracene unit is important for the fluorescence properties and does not play a role in binding of the metal ion to $\mathrm{C}=\mathrm{S}$. Using the argument stated above, we consider only the 1,3-dithiole-2-thione region as the reaction center for the mechanistic study (figure $2 \mathrm{a}$ ).

In figure $2 b$ we show the three possible binding sites present for metal ion complexation. We have optimized the geometries of the molecule in the presence of the metal ions at these three different sites. For both $\mathrm{As}(\mathrm{III})$ and $\mathrm{Hg}(\mathrm{II})$, the lowest energy form corresponds to the metal ions being bound to site 1 instead of 2 or 3 . Thus, the reaction could pro- ceed via a nucleophillic attack as shown in scheme 1 . We find that the metal reactant complexation leads to the creation of an electron deficient carbon center. The Mulliken charge decreases from -0.59 e to $-0.47 \mathrm{e}$ in $\mathrm{As}$ (III) and -0.59 e to -0.53 e in $\mathrm{Hg}$ (II) creating electron deficiency at the carbon atom favouring a neucleophillic attack by water.

The lability of the nucleophilic attack by a water molecule on the complex will crucially depend on the stability of the metal-ligand complex. The binding energies for the various metal ions are calculated as $\Delta E_{\text {binding }}=E_{\text {complex }}-\left(E_{\text {metal }}+E_{\text {reactant }}\right)$, where $E_{\text {complex }}$ is the energy of the metal-reactant complex, $E_{\text {metal }}$ is the energy of the isolated metal and $E_{\text {reactant }}$ is the energy of the isolated reactant. We report the binding energies in parentheses, with stability following the trend As(III) $(-21.83 \mathrm{eV})>\mathrm{Ni}(\mathrm{II})(-9.67 \mathrm{eV})>\mathrm{Hg}$ (II) $(-7.39 \mathrm{eV})>\mathrm{Cd}$ (II) $(-6.81 \mathrm{eV})>\mathrm{Pb}$ (II) $(-5.38 \mathrm{eV})$. Note that a more negative value means a more stable metal-reactant complex. Thus, the As(III)-molecule complex is the most stable one and thus the molecule would bind strongest with As(III)-ion. However, we find that the Ni(II)-ion binds more strongly with the molecule than the $\mathrm{Hg}$ (II) ion. This result is counterintuitive as the dosimeter has been experimentally reported to be selective to $\mathrm{Hg}$ (II). But if the $\mathrm{Ni}(\mathrm{II})$-reactant complex is more stable compared to the $\mathrm{Hg}(\mathrm{II})$-reactant complex, then in a solution containing both $\mathrm{Ni}(\mathrm{II})$ and $\mathrm{Hg}(\mathrm{II})$, we would expect the formation of the Ni(II)-reactant complex to be more favoured over the formation of the $\mathrm{Hg}$ (II)reactant complex, thereby affecting the dosimeter action. To resolve this apparent contradiction, we look into the reaction mechanism in the presence of water. We note that the first step of the reaction mechanism involves the displacement of a solvent molecule by a reactant molecule in the coordination sphere. Thus it becomes important to look into the energetics of the water-reactant exchange mechanism. For this, we explicitly take into account the 
coordination sphere of the metal ion in our further calculations.

\subsection{Coordination sphere}

All metals are associated with a definite coordination sphere that governs the reactivity of the metals. ${ }^{22}$ Since, we are investigating the presence of the metal ion in water, the formation of the metal-water complex precedes the formation of the metalreactant complex. The formation of a metal-reactant complex will then involve the replacement of a water molecule from the metal coordination sphere. $\mathrm{Hg}$ (II) favours tetrahedral coordination ${ }^{23(a)}$ and $\mathrm{Ni}(\mathrm{II})$ favours the octahedral coordination. ${ }^{23(b)}$ The optimized structures of $\mathrm{Hg}$-(Reactant $)_{4}$ and $\mathrm{Hg}-\left(\mathrm{H}_{2} \mathrm{O}\right)_{4}$ are found to retain the tetrahedral geometry while $\mathrm{Ni}$-(Reactant $)_{6}$ and $\mathrm{Ni}-\left(\mathrm{H}_{2} \mathrm{O}\right)_{6}$ maintain an octahedral geometry (figure 3). In the aquo-complex, $\mathrm{Hg}$ (II) has a tetrahedral coordination, with the $\mathrm{Hg}-\mathrm{O}$ bond length being $2.31 \AA$ and the $\mathrm{O}-\mathrm{Hg}-\mathrm{O}$ bond angles being $109.9^{\circ}, 110.8^{\circ}, 106.3^{\circ}, 112.5^{\circ}, 110.8^{\circ}$ and $107.7^{\circ}$. For the metal-reactant complex, the $\mathrm{Hg}-\mathrm{S}$ bond length is $2.78 \AA$ and the $\mathrm{S}-\mathrm{As}-\mathrm{S}$ angles are $107.9^{\circ}, 105.9^{\circ}, 114.9^{\circ}, 105.5^{\circ}, 107.3^{\circ}$ and $113.3^{\circ}$. The Ni(II) aquo-complex has an octahedral coordination with the $\mathrm{Ni}-\mathrm{O}$ bond length being $2 \cdot 10 \AA$ in the equatorial direction and $2.05 \AA$ in the axial direction. The $\mathrm{O}-\mathrm{Ni}-\mathrm{O}$ (opposite end $\mathrm{O}$ ) bond angles are all $180^{\circ}$ describing a perfect octahedral geometry. For the metal-reactant complex, the $\mathrm{Ni}-\mathrm{S}$ bond

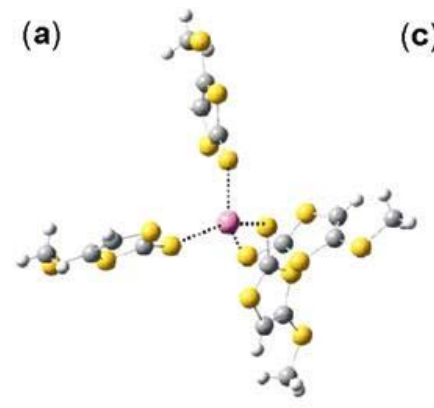

(b)

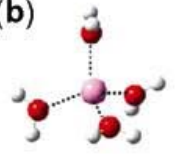

(c)

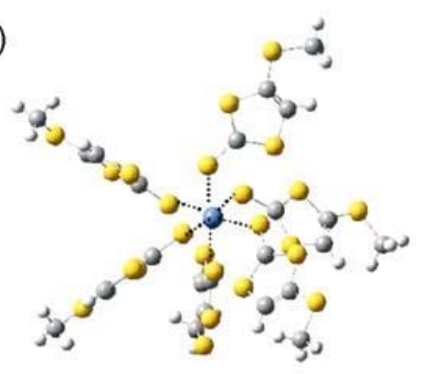

(d)

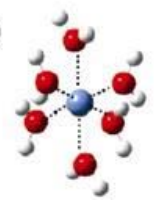

Figure 3. Optimized geometries of the metal-reactant and metal-water complexes. (a) Hg-(Reactant) ${ }_{4}$, (b) $\mathrm{Hg}$ $\left(\mathrm{H}_{2} \mathrm{O}\right)_{4}$, (c) Ni-(Reactant $)_{6}$ and $\mathrm{Ni}-\left(\mathrm{H}_{2} \mathrm{O}\right)_{6}$. Colour code: Pink, Hg; Blue, Ni; Red, O; Grey, C; Yellow, S and White, $\mathrm{H}$. lengths are $2.54 \AA$ in the axial direction and $2.57 \AA$ in the equatorial direction and the $\mathrm{O}-\mathrm{Ni}-\mathrm{O}$ (opposite end $\mathrm{O}$ ) bond angles are $171.2^{\circ}, 171.6^{\circ}$ and $173.0^{\circ}$ describing a distorted octahedron.

We calculate the energy required for the complete exchange of the water $\rightarrow$ reactant coordination sphere to analyse the stability associated with the formation of the metal-reactant complex. We define $\Delta E_{\text {tetrahedral }}$ for $\mathrm{Hg}(\mathrm{II})$ and $\Delta E_{\text {octahedral }}$ for $\mathrm{Ni}(\mathrm{II})$ to calculate the energy required for a single water $\rightarrow$ reactant exchange process. We find that,

$$
\begin{aligned}
\Delta E_{\text {tetrahedral }}= & {\left[E \mathrm{Hg}-(\text { Reactant })_{4}+4 \times E\left(\mathrm{H}_{2} \mathrm{O}\right)\right] } \\
& -\left[E \mathrm{Hg}-\left(\mathrm{H}_{2} \mathrm{O}\right)_{4}+4\right. \\
& \times \mathrm{E}(\text { Reactant })]=-47.73 \mathrm{kcal} / \mathrm{mol} . \\
\Delta E_{\text {octahedral }}= & {\left[\mathrm{ENi}-(\text { Reactant })_{6}+6 \times \mathrm{E}\left(\mathrm{H}_{2} \mathrm{O}\right)\right] } \\
& -\left[\mathrm{E} \mathrm{Ni}-\left(\mathrm{H}_{2} \mathrm{O}\right)_{6}+6 \times \mathrm{E}(\text { Reactant })\right] \\
= & 4.02 \mathrm{kcal} / \mathrm{mol} .
\end{aligned}
$$

The negative sign indicates stabilization. The sign and magnitude of $\Delta E_{\text {tetrahedral }}$ clearly indicate that the formation of the $\mathrm{Hg}$-Reactant is a highly favoured process, while with positive $\Delta E_{\text {octahedral }}$ the formation of the octahedral Ni-reactant complex is not a favoured process. We calculate the stabilization energy as $E_{\text {stabilization }}=\Delta E_{\text {tetrahedral }}-\Delta E_{\text {octahedral }}$ to be $-51.75 \mathrm{kcal} /$ mol. The negative value of the stabilization energy indicates that the exchange process for a tetrahedral coordination is more favoured as compared to the octahedral coordination. These results clearly indicate that it is necessary to take into account the entire coordination sphere to describe the reaction mechanism. We also find that it is important to consider the metal-solvent complex as the first step to describe the reaction mechanism.

\subsection{Arsenic detection}

The successful description of the selectivity criteria for $\mathrm{Hg}^{2+}$ detection and the binding studies encouraged us to probe the chemodosimeter for $\mathrm{As}^{3+}$ detection. As(III) has a strong affinity towards sulphur ${ }^{24}$ and this large affinity of arsenic towards sulfur causes many health disorders as it disrupts the disulfide bond in the body. ${ }^{25}$ We utilize this strong affinity of As(III) towards sulfur for studying the chemodosimeter for As(III) detection. Since the chemodosimeter for $\mathrm{Hg}(\mathrm{II})$ detection is also dependent on the thiophillic affinity of the metal ion, we compare the 
thiophillic affinities of $\mathrm{Hg}$ (II) and As(III) for the dosimeter action.

Recent spectroscopic and theoretical studies have demonstrated that $\mathrm{As}(\mathrm{OH})_{3}$ is the stable structure of arsenite at neutral $\mathrm{pH}$ and it prefers the trigonal pyramidal coordination similar to $\mathrm{N}$ and $\mathrm{P}$ due to the presence of a lone pair. ${ }^{26}$ As in the previous case, we calculate the energies required for the formation of As- $\left(\mathrm{H}_{2} \mathrm{O}\right)_{3}$ and $\mathrm{As}(\text { reactant })_{3}$ to estimate the energy required for a complete exchange of the water $\rightarrow$ reactant coordination sphere. The optimized structures of As- $\left(\mathrm{H}_{2} \mathrm{O}\right)_{3}$ and $\mathrm{As}(\text { reactant })_{3}$ retain the trigonal pyramidal geometry as shown in figure 4 . Calculation of $\Delta E_{\text {trigonal }}=\left[E\right.$ As $-(\text { Reactant })_{3}+3 \times \mathrm{E}$ $\left.\left(\mathrm{H}_{2} \mathrm{O}\right)\right]-\left[E \mathrm{As}-\left(\mathrm{H}_{2} \mathrm{O}\right)_{3}+3 \times E\right.$ (Reactant) $]$, gives us $\Delta E_{\text {trigonal }}=-221.92 \mathrm{kcal} / \mathrm{mol}$ and the stabilization energy defined as $E_{\text {stabilization }}=\Delta E_{\text {trigonal }}-\Delta E_{\text {tetrahedral }}$ to be $-174.19 \mathrm{kcal} / \mathrm{mol}$ (negative sign indicates stabilization). This stabilization over the tetrahedral coordination clearly favours the formation of the As(III) complex over $\mathrm{Hg}$ (II) and other metal ion complexes. Thus, we find that the chemodosimeter should be highly selective towards As(III) detection. To have a complete understanding of the reaction mechanism and the intermediates involved in the reaction pathway we have analysed the complete reaction pathways.

\subsection{Reaction pathway}

We have analysed the reaction pathway for the conversion of reactant $\rightarrow$ product. Note that, for this

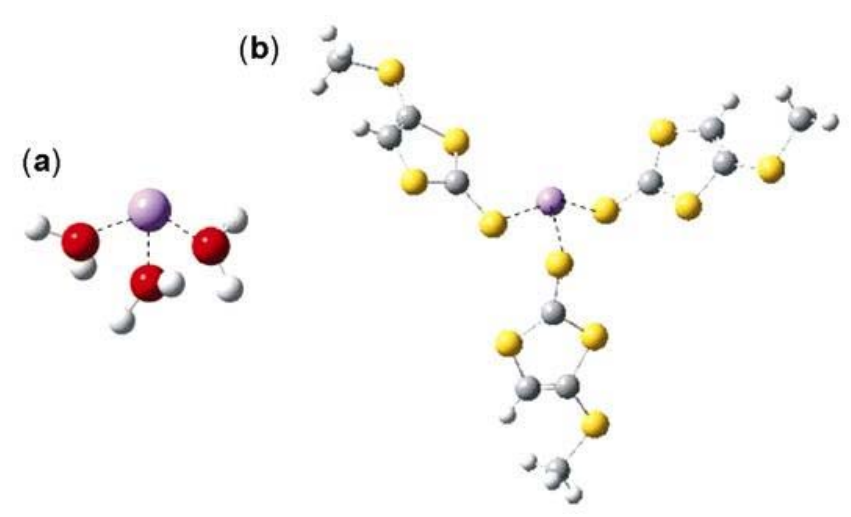

Figure 4. Optimized geometries of the metal-reactant and the metal-water complexes. (a) $\mathrm{As}-\left(\mathrm{H}_{2} \mathrm{O}\right)_{3}$ and (b) As-(Reactant) $)_{3}$. Colour code: Purple, As; Red, O; Grey, $\mathrm{C}$; Yellow, $\mathrm{S}$ and White, H. In the aquo-complex, $\mathrm{As}^{3+}$ has a trigonal pyramidal coordination, with the As-O bond length being $1.95 \AA$ and the $\mathrm{O}-\mathrm{As}-\mathrm{O}$ bond angle being $92 \cdot 2^{\circ}$. In the metal-reactant complex, the As-S bond lengths are $2.50 \AA$ and the $\mathrm{S}-\mathrm{As}-\mathrm{S}$ angles are $93.2^{\circ}$, $103.9^{\circ}$ and $101^{\circ}$. conversion to take place we need to proceed sequentially from various intermediate states on the energy landscape. As described earlier, due to the presence of water as a solvent, we have started with the metal-water complex as the initial state. We impose a few constraints over the reactions to narrow down our search of the intermediate states and obtain an energy landscape.

- We allow the exchange of only one water molecule with one reactant at a given step.

- We do not allow the exchange of a water molecule with a product molecule.

- Upon the conversion of a reactant to product, we have the product occupying the position of the reactant molecule in the coordination sphere.

To compare the energies of the various structures at the same footing, we calculate the energy of formation of each intermediate structure. The water-metal complex is assigned an energy value $0.0 \mathrm{eV}$ and all the other formation energies are scaled with respect to the energy of the initial water-metal complex. The formation energy is calculated as defined in scheme 2. The geometries of all the allowed intermediate structures were obtained by full optimization of the coordinates without any geometrical constraints. Using the formation energies of the various intermediate states, we obtain the energy landscape for the $\mathrm{As}^{3+}$ and $\mathrm{Hg}^{2+}$ pathways. We have plotted the same in figures 5 and 6 respectively.

The negative energy scale is a measure of the stabilization of the intermediate structures; the $\mathrm{As}^{3+}$ reaction pathway shows a steep descent indicating the stabilization of the intermediates. We find the metalreactant complex $\mathrm{AsR}_{3}$, to be the most stable intermediate on the energy landscape; the stabilization

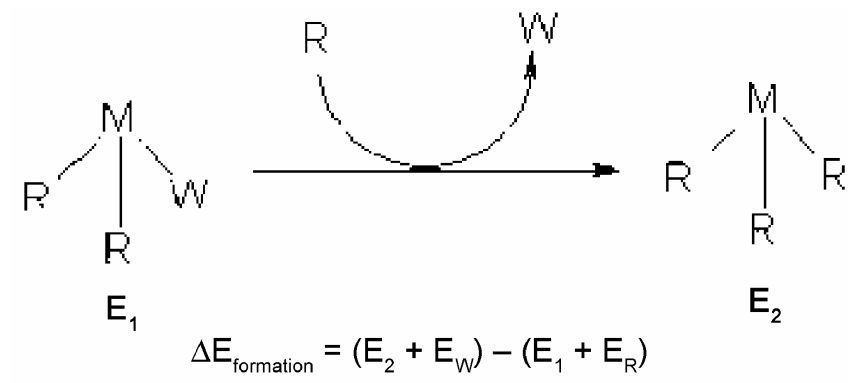

Scheme 2. Formation energy of the chemical transformation from 1 to 2 . Code: M, metal ion; R, Reactant; W, Water. 


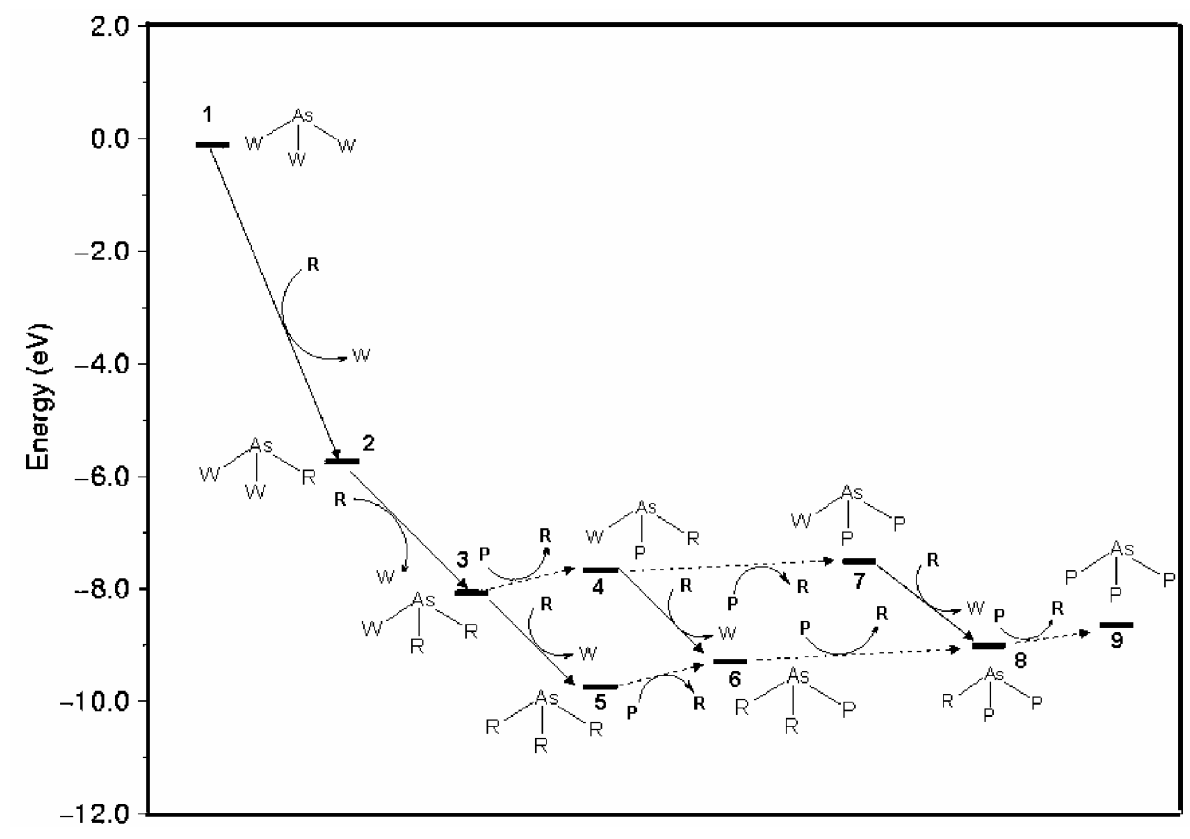

Figure 5. Reaction Pathway for the $\mathrm{As}^{3+}$ reaction. The energies are scaled with respect to $\mathrm{As}\left(\mathrm{H}_{2} \mathrm{O}\right)_{3}$. Solid arrow: Reactant-water exchange mechanism, Broken arrow: reactant-product chemical transformation. R, Reactant; P, Product; W, Water. Energies are reported in $\mathrm{eV}$.

gained being $-211.22 \mathrm{kcal} / \mathrm{mol}$. On analysing the reaction pathway, we find that we achieve $66 \%$ efficiency but not $100 \%$ efficiency, as the formation of the complete metal-product $\mathrm{AsP}_{3}$ complex is not allowed thermodynamically. The energy cost for the transformation of $\mathrm{AsP}_{2} \mathrm{R} \rightarrow \mathrm{AsP}_{3}$ turns out to be $8.25 \mathrm{kcal} / \mathrm{mol}$, which cannot be accounted by thermal energy. We find that under normal conditions, the reaction pathway facilitates the transformation of two reactant molecules to product molecules, thereby, achieving $66 \%$ efficiency. We trace out the possible pathways for reaching $\mathrm{As}_{2} \mathrm{R}$ on the energy landscape. The only route for the formation of $\mathrm{AsP}_{2} \mathrm{R}$ is 1-2-3-4-7-8 (see figure 5). This route involves two destabilizing transitions and one stabilizing transition. The two destabilizing transition being $3 \rightarrow 4$ and $4 \rightarrow 7$. The energy costs associated with these transitions are $8.86 \mathrm{kcal} / \mathrm{mol}$ and $3.68 \mathrm{kcal} / \mathrm{mol} \mathrm{re}-$ spectively. We find that the final transition $6 \rightarrow 8$ overcomes the destabilization associated with previous transitions as the stabilization associated with this transition is $-34.50 \mathrm{kcal} / \mathrm{mol}$. Thus, the intermediate states 4 and 7 act as transition states in the reaction pathway with an acceptable energy cost associated with accessing the states. The other routes 1-2-3-5-6-8 and 1-2-3-4-6-8 are not feasible as the last step involves accessing a transition state and does not have stabilization associated with the formation of a final state. The first route also requires overcoming a deep potential barrier created by the 3-5-6 transition, the energy cost for going from $5 \rightarrow 6$ being $10.68 \mathrm{kcal} / \mathrm{mol}$ (positive value indicating destabilization) which is not compensated by any transformation later in the pathway. The second route also encounters a potential barrier similar to that for the first route associated with the $6 \rightarrow 8$ transition, the energy cost associated with the transition being $3.68 \mathrm{kcal} / \mathrm{mol}$. Although we achieve only $66 \%$ efficiency, note that there is only one path allowed for the formation of $\mathrm{AsP}_{2} \mathrm{R}$, and there are no competing processes that can reduce the efficiency of the reaction.

On the contrary, the $\mathrm{Hg}^{2+}$ pathway does not show the steep descent associated with $\mathrm{As}^{3+}$ pathway. The most stable intermediate on the energy landscape is the $\mathrm{HgR}_{4}$ complex; the stabilization gained being only $-47.40 \mathrm{kcal} / \mathrm{mol}$ whereas the stabilization gained by $\mathrm{AsR}_{3}$ was $-211.22 \mathrm{kcal} / \mathrm{mol}$. Similar to the $\mathrm{As}^{3+}$ pathway, we do not achieve $100 \%$ efficiency even in $\mathrm{Hg}^{2+}$ pathway, as the formation of $\mathrm{HgP}_{4}$ involves a destabilizing transformation, with an energy cost of $6.06 \mathrm{kcal} / \mathrm{mol}$ associated with it. We find that there exist two routes for the formation of $\mathrm{HgP}_{3} \mathrm{R}$ : 1-2-45-6-10-13-14 and 1-2-3-5-6-10-13-14. The first 


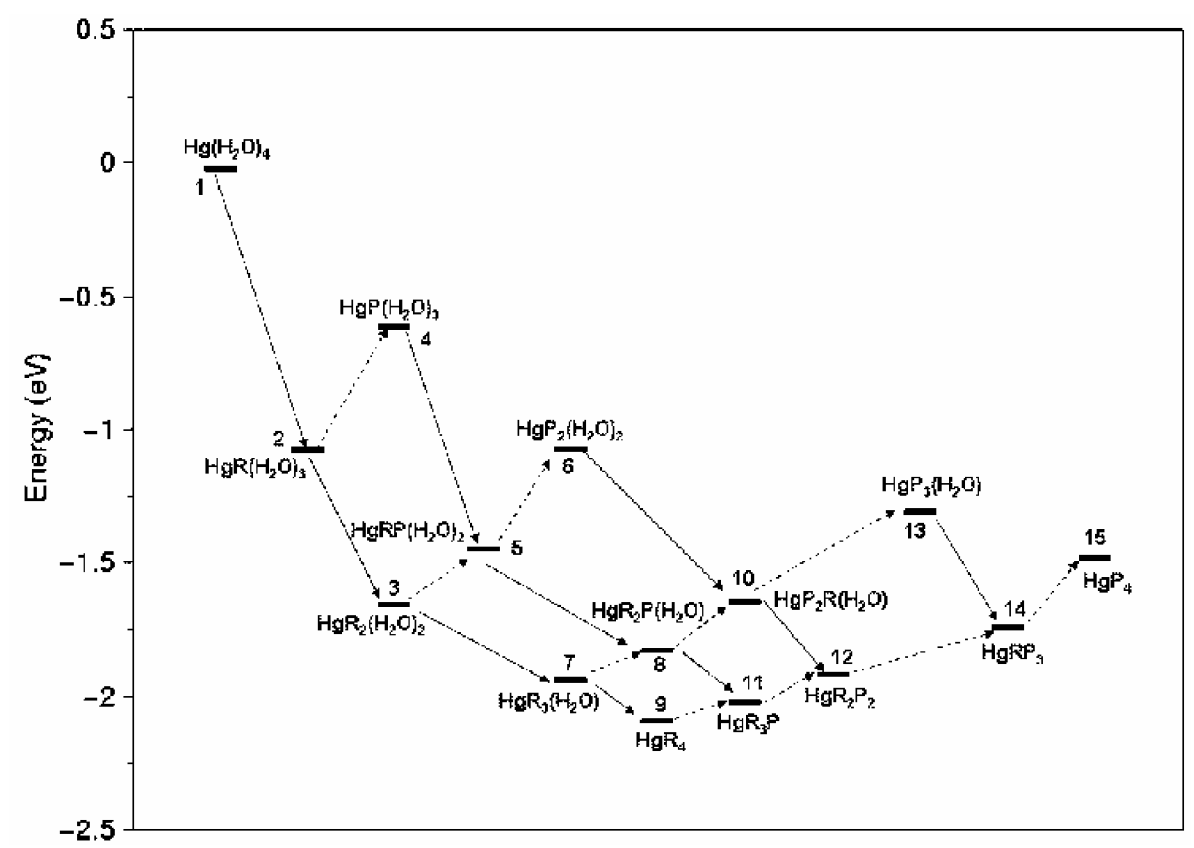

Figure 6. Reaction Pathway for the $\mathrm{Hg}^{2+}$ reaction. The energies are scaled with respect to the $\mathrm{Hg}\left(\mathrm{H}_{2} \mathrm{O}\right)_{4}$. Solid arrow: Reactant-water exchange mechanism, Broken arrow: reactant-product chemical transformation. R, Reactant; P, Product; W, Water. Energies are reported in eV.

route involves crossing three potential barriers associated with the transitions $2 \rightarrow 4,5 \rightarrow 6$ and $10 \rightarrow 13$. The energy costs associated with the three transitions being $10.70 \mathrm{kcal} / \mathrm{mol}, 8.65 \mathrm{kcal} / \mathrm{mol}$ and 7.78 $\mathrm{kcal} / \mathrm{mol}$ respectively. The stabilizing transitions $4 \rightarrow 5,6 \rightarrow 10$ and $13 \rightarrow 14$, have the energy costs $-19.18 \mathrm{kcal} / \mathrm{mol},-13.22 \mathrm{kcal} / \mathrm{mol}$ and $-10 \cdot 10 \mathrm{kcal} / \mathrm{mol}$ associated with them. Thus, we find that even though the transitions are allowed, the deep energy barriers associated with the pathway do not allow smooth transitions. The second route has an even larger energy barrier of $13.46 \mathrm{kcal} / \mathrm{mol}$ associated with the transition 2-3-5-6-10, reducing its efficiency. Thus we find that the formation of $\mathrm{HgP}_{4}$ and $\mathrm{HgRP}_{3}$ are not thermodynamically favoured. We analyse the formation of $\operatorname{HgR}_{2} \mathrm{P}_{2}$ which would be a $50 \%$ efficiency process. The most suitable route for the formation of $\operatorname{HgR}_{2} \mathrm{P}_{2}$ is 1-2-3-5-8-10-12 which involves two destabilizing transitions $3 \rightarrow 5$ and $8 \rightarrow 10$, the energies associated with these transitions being $4.81 \mathrm{kcal} / \mathrm{mol}$ and $4.25 \mathrm{kcal} / \mathrm{mol}$ respectively. This makes the transition route a favourable route for the formation of $\operatorname{HgR}_{2} \mathrm{P}_{2}$; but as discussed earlier the formation of $\mathrm{HgR}_{2} \mathrm{P}_{2}$ accounts for only $50 \%$ efficiency.

Thus comparing the two pathways we find that the stabilization associated with the $\mathrm{As}^{3+}$ pathway over- whelms the stabilization associated with the $\mathrm{Hg}^{2+}$ pathway. The formation of the metal-reactant species as the most stable species on the energy landscape illustrates the strong affinity of Sulphur for $\mathrm{Hg}^{2+}$ and $\mathrm{As}^{3+}$, but the differences in the formation energies $-2.06 \mathrm{eV}$ for $\mathrm{Hg}^{2+}$ and $-9.16 \mathrm{eV}$ for $\mathrm{As}^{3+}$ show that $\mathrm{As}^{3+}$ has a stronger affinity compared to $\mathrm{Hg}^{2+}$. The $\mathrm{As}^{3+}$ pathway achieves $66 \%$ efficiency compared to only $50 \%$ efficiency achieved by the $\mathrm{Hg}^{2+}$ pathway. Energetically, also we find that the $\mathrm{As}^{3+}$ is a more favourable pathway with shallow energy barriers associated with the transition states.

\section{Conclusion}

We have investigated the mechanistic basis for the chemodosimeter action of 1,3-dithiole-2-thione. We find that the chemodosimeter action, which is dependent on the strong thiophillic affinity of the metal ion also critically depends on the solvent coordination. The coordination sphere plays the vital role in controlling the reaction. Our calculations reveal that the 1,3-dithiole-2-thione chemodosimeter is more selective to $\mathrm{As}$ (III) than $\mathrm{Hg}$ (II). Complete reaction pathway analysis reveals that the $\mathrm{As}^{3+}$ pathway is associated with $66 \%$ efficiency whereas the $\mathrm{Hg}^{2+}$ pathway is associated with only $50 \%$ effi- 
ciency. We also note that further chemical modifications on the molecule by substitution of electron withdrawing groups may further enhance the activity of the chemodosimeter. The experimental verifications of our proposed results are currently underway. With the studied dosimeter being reported to detect $\mathrm{Hg}^{2+}$ at very low concentrations $\left(5 \times 10^{-8} \mathrm{M}\right),{ }^{17(\mathrm{~d})}$ we hope that our work results in the successful synthesis of inexpensive chemodosimeters for $\mathrm{As}^{3+}$ detection that can ensure safe drinking water for a large human population.

\section{Acknowledgements}

SKP thanks Council of Scientific and Industrial Research (CSIR), Department of Science and Technology (DST), Government of India for research grants. SSM and AD thank CSIR for SRF Fellowships. UH thanks JNCASR for the POCE fellowship. The authors express gratitude to Prof. C N R Rao, for his continued support and encouragement.

\section{References}

1. (a) Kinniburgh D G and Smedley P L (eds) 2001 Arsenic contamination of groundwater in Bangladesh (British Geographic Survey Report WC/00/19); (b) Charlet L and Polya D A 2006 Elements 291

2. (a) Smith A H, Lingas E O and Rahaman M 2000 Bull. WHO 78 1093; (b) Lepkowski W 1998 Chem. \& Eng. News 7627

3. Tareq S M, Safiullah S, Anawar H M, Rahman M M and Ishizuka T 2003 The science of the total environment 313213

4. Analysis and practice in water resources engineering for disaster mitigation 2003 New Age International, Sanyal S K and Nasar S K T 1216

5. (a) Nickson R, McArthur J, Burgess W, Ahmed K M, Ravenscroft P and Rahman M 1998 Nature 395 338; (b) Aggarwal P K, Basu A R and Kulkarni K M 2003 Science 300584

6. Acharyya S K, Chakraborty P, Lahiri S, Raymahashay B C, Guha S and Bhowmik A 1999 Nature 401 545; (b) Dixit S and Hering J G 2003 Envt. Sci. \& Technol. 374182

7. (a) Harvey F C et al 2002 Science 298 1602; (b) Harvey F C et al 2005 Comptus Rendus Geoscience 337 285

8. (a) Hopenhayn C 2006 Elements 2 103; (b) Arsenic and arsenic compounds, International Program on Chemical Safety (IPCS), 2nd edn 2001; (c) Chen C J, Kuo T L and Wu M M 1998 Lancet 1414

9. (a) Arsenic: Environment and Health Aspects with Special Attention to Groundwater in SE Asia (eds) D Chakraborti, A Hussam and A Alauddin (Mercel Dekker, USA) 2003 38; (b) Sun G 2004 Toxicol. \&
Appl. Pharmacol. 198 268; (c) Yang C Y, Chang C C, Tsai S S, Chuang H Y, Ho C K, Wu and T N 2003 Environment. Res. 91 29; (d) Yu R C, Hsu K H, Chen C J and Froines J R 2000 Cancer Epidemiol. Biomarkers and Prevention 91259

10. (a) Chris Le, X and Mingsheng Ma 1998 Anal. Chem. 70 1926; (b) Larsen E H, Pritzl G and Hansen S H 1993 J. Anal. Atomic Spectrometry 8 1075; (c) McSheehy S and Szpunar J 2000 J. Anal. Atomic Spectrometry 1579

11. (a) Becker-Ross H, Florek S and Heitmann U $2000 \mathrm{~J}$. Anal. Atomic Spectrometry 15 137; (b) Krachler M, Emons H, Barbante C, Cozzi G, Cescon P and Shotyk W 2002 Anal. Chim. Acta 458387

12. (a) Amjad S, Chandrasekaran N, Anuradha C D and Seishiro H 2002 Appl. Organomet. Chem. 16 202; (b) Chatterjee A, Shibata Y, Yoshinaga J and Morita M 2000 Anal. Chem. 72 4402; (c) Karthikeyan S and Hirata S 2003 Anal. Lett. 362355

13. (a) Haishi C and Michael D H 2004 J. Fluores. 14 569; (b) Goldenberg L M, Bryce M R and Petty M C 1999 J. Mater. Chem. 9 1957; (c) Bell T W and Hext N M 2004 Chem. Soc. Rev. 33 589; (d) Tanabe T, Touma K,Hamasaki K and Ueno A 2001 Anal. Chem. 731877

14. (a) Guo X, Qian X and Jia L $2004 \mathrm{~J}$. Am. Chem. Soc. 126 2272; (b) Moon S Y, Cha N R, Kim Y H and Chang S 2004 J. Org. Chem. 69 181; (c) Nolan E M and Lippard S J $2003 \mathrm{~J}$. Am. Chem. Soc. 12514270

15. (a) Ros-Lis J V, Martínez-Máňez R, Rurack K, Sancenón F, Soto J and Spieles M 2004 Inorg. Chem. 435183 (b) Descalzo A B, Martínez-Máňez R, Radeglia R, Rurack K and Soto J $2003 \mathrm{~J}$. Am. Chem. Soc. 1253418

16. (a) Jiménez D, Martínez-Máňez R, Sancenón F, RosLis J V, Benito A and Soto J $2003 \mathrm{~J}$. Am. Chem. Soc. 125 9000; (b) Xu S, Chen K and Tian H $2005 \mathrm{~J}$. Mater. Chem. 15 2676; (c) Chow C, Brenda K W, Chiu Michael H W, Lam and Wai-Yeung Wong $2003 \mathrm{~J}$. Am. Chem. Soc. 125 7802; (d) Hennrich G, Walther W, Resch-Genger U and Sonnenschein H 2001 Inorg. Chem. 40641

17. (a) Ros-Lis, J V, Marcos D M, Martínez-Máňez R, Rurack K and Soto J 2005 Angew. Chem. 44 4405; (b) Young-Keun Yang, Keun-Jeong Yook and Tae J 2005 J. Am. Chem. Soc. 127 16760; (c) Liu B and Tian H 2005 Chem. Comm. 3156; (d) Zhang G, Zhang D, Yin S, Yang X, Shuai Z and Zhu D 2005 Chem. Comm. 2161

18. Gaussian 03, Revision C.02, Frisch M J et al 2004 Gaussian, Inc., Wallingford CT

19. (a) Becke A D 1993 J. Chem. Phys. 98 5648; (b) Lee D, Yang W, Parr R G 1988 Phys. Rev. B37 785

20. (a) Hay P J and Wadt W R $1985 \mathrm{~J}$. Chem. Phys. 82 270; (b) Hay P J and Wadt W R 1985 J. Chem. Phys. 82 299; (c) Wadt W R and Hay P J 1985 J. Chem. Phys. 82284

21. Casida ME, Jamorski C, Casida K C and Salahub D R 1998 J. Chem. Phys. 1084439

22. (a) Inorganic chemistry (eds) E J Huheey, E A Keiter and L R Keiter 1993 (Addison-Wesley), 4th edn, 
pp 387-459; (b) Concise inorganic chemistry 1996 (ed.) J D Lee (Blackwell Science) Fifth edn, p. 194236

23. (a) Chemistry of elements (eds) Grenwood N N, Earnshaw A 1997 (Butterworth Heinmann) Second edn, pp 1218-1221; (b) Chemistry of elements (eds) N N Grenwood and A Earnshaw 1997 (Butterworth Heinmann), Second edn, pp. 1156-1166.

24. (a) Carter D E, Aposhian H V and Gandolfi A J 2003 Toxicol. Appl. Pharmacol. 193 309; (b) Mineral chemistry of metal sulfides (eds) D J Vaughan, D Wallschlager and R G Ford 1978 (Cambridge University Press)

25. (a) Arsenic; Medical and biological effects of environmental pollutants, national research council, National Academy Press 1977; (b) Arsenic in Drinking Water, National research Council, National Academy Press, 1999

26. Solis A R, Mukopadhyay R, Rosen B P and Stemmler T L 2004 Inorg. Chem. 432954 